\title{
Breastfeeding Counselling can be a Matter of Interprofessional Communication
}

\author{
Sofia Zwedberg \\ Department of Women's and Children's Health, Karolinska Institutet, Stockholm, Sweden \\ sofia.zwedberg@ki.se
}

Received date: 4 November 2013; Accepted date: 20 January 2014; Published date: 21 February 2014

Academic Editor: Anette C. Ekström

Copyright @ 2014. Sofia Zwedberg. Distributed under Creative Commons CC-BY 3.

\begin{abstract}
The need of breastfeeding mothers often remains unmet. Breastfeeding has both biological and emotional impacts on the mother's and the child's health. Breastfeeding is a "negotiation process" triggered by interactive initiatives of the infant and the caregiver's interpretations and responses thereto. A parallel negotiation process is evident between a mother and her midwife. The Swedish Act on Patient Safety decrees that planned care should include maternal consultation. The aim of this study was to describe health care professionals' own reflections on given formula of infants after birth and differences in how midwives perceived their responsibilities, and how they valued patient participation, in caring situations regarding breastfeeding. A total of 39 midwives wrote reflections on the degree of care they used when promoting breastfeeding; the data were analysed hermeneutically. The hospital hierarchy influenced midwives' work and how midwives co-operated with other professionals. It also influenced what participation and responsibility can mean for a midwife, and three themes emerged as evident: asymmetrical responsibility, symmetrical responsibility, and abdication of responsibility. Midwives focused principally on how their actions were viewed by medical professionals; this was paralleled by the treatment of mothers and newborns. It is important to realise that breastfeeding poses a challenge to interprofessional co-operation and a good communication between doctors and midwives; otherwise they will be losing the holistic view.
\end{abstract}

Keywords: breastfeeding, communication, interprofessional, patient participation, responsibility.

\section{Introduction}

Midwife support is both very valuable and under-recognized (Simkin 1996). The needs of breastfeeding mothers often remain unmet (McInnes \& Chambers 2008; Zwedberg 2010: Schmied et.al 2011).
Professional emotional support, thus from someone who patiently listens and seeks to understand, seems to be crucial in the reestablishment of self-esteem in new mothers (Dykes et.al 2003; Gill 2001).

Breastfeeding has both biological and emotional impacts on the mother's and the 
child's health. Close physical contact with the baby and the particular manner in which a child is breastfed are important in bonding, and can make the attachment going easier between the mother and the child (Klaus et.al 1996; Ljungberg 1995). Such bonding increases the chance that a child will continue to receive maternal care; this is a mutual relationship (Berg 2005). Both general care and breastfeeding are interactional in nature and can be regarded as the outcomes of a "negotiation process" triggered by interactive initiatives of the infant and the caregiver's interpretations and responses thereto. A parallel negotiation process is evident between a mother and her midwife. New mothers seek role models (Stern et.al 1999) and midwives are trusted givers of professional care. If a midwife is not supportive of a process, the mother-infant interaction can be seriously affected (Karl et.al 2006). Two Meta synthesis studies declare breastfeeding consultations are inadequate often because of time pressure and inadequate staffing; and note also there are many not supportive midwives (McInnes \& Chambers 2008; Schmied et.al 2011).

The Swedish Act on Patient Safety (2010) decrees that planned care should include maternal consultation. A midwife is endowed with professional knowledge and values. It is thus best if infant care planning features a dialogue between a mother and her midwife; the mother should be involved to influence the plan (The National Board of Health and Welfare 2012).

Actions are influenced by intentions and values (Alexandersson 1994; Uljens 1989) and develop dialectically within a particular context. How midwives work with mothers and children is therefore a parallel process of how they themselves can communicate with other professionals. Few studies have explored whether midwives assume the responsibility to share information with new mothers and whether they involve mothers to participate in decision-making. The aim of this study was thus to describe health care professionals' own reflections on given formula to infants after birth and differences in how midwives perceived their responsibilities, and how they valued woman participation, in caring situations regarding breastfeeding.

\section{Method}

A hermeneutical approach (Ricoeur 1993) was chosen to explore whether midwives included mothers to share in decisionmaking regarding the care of their newborns. Hermeneutics is a science that explores real-world experiences to gain a deeper understanding of the human condition (Ödman 2007). Data were collected from 39 midwives who provided 101 handwritten descriptions of the care given to new mothers whose infants were put on formula. Written texts were interpreted via the study of textual structure and internal logic (Ricoeur 1993).

\section{Setting}

The study was conducted in a maternity hospital in Stockholm, Sweden, during the spring of 1999. About 5,000 infants are delivered annually in the hospital. Both normal and more complicated deliveries are conducted. Midwives and doctors work closely together. Midwives are responsible for normal deliveries and co-operate in the care of complicated cases. All infants were examined once by a neonatologist during the second day after birth. No further examination was performed if everything was normal; further attention was given if necessary.

\section{Design and Sample Selection}

Seven days in the interval January-April were randomly chosen, and the numbers of children receiving formula on those days were counted (Zwedberg et.al 2003). Also, midwives, who were responsible for children receiving formula, were asked to write anonymous brief descriptions (in their own words) of the diagnosis, treatment, and care given thus far, and the results of actions taken. They were also asked to reflect personally on the positive or negative effects of the move to formula on the mother-child couple and whether they believed that an alternative action would have yielded equal or better results. The descriptions were collected at the end of the work shift. Sometimes the reflections 
mirrored the care given personally and sometimes the care given by colleagues. All midwives were given the option of recording their opinions in writing (in other words, this was not compulsory), and were allowed to write separate accounts for each child in their care who was receiving formula. Each midwife was given an anonymous ID number to allow multiple accounts from a single individual to be read together, irrespective of the dates of collection. All accounts were collected by an independent midwife and handed to SZ, without the key list, after the last survey date. A total of 101 accounts of varying length, from a half-page to four pages, were obtained from 39 midwives.

\section{Analysis}

The analysis commenced with and was based on a previous study conducted using the same material (the written reflections). Midwives treated mother-child couples in different ways, depending on how the midwives viewed themselves and the couple (Zwedberg et.al 2011). Were the midwife and the couple subjects or objects? This raised a new question: What causes a midwife to see herself as an object or subject? In an effort to detect underlying values/attitudes that might influence this choice, a second analysis of the data generated in the study above has been used in this paper taking a different approach to analysis, using interpretations of words and formulations (Ricoeur 1993). All texts were read again, now with a focus on how midwives expressed their reflections on the nursing care given. Midwives often mentioned relationships with other health care professionals followed by reflections upon how care was designed. To facilitate understanding of the quotations, I positioned them in the context of observations that I made and informal discussions in which I participated during my time as a midwife. Thus, I was not an objective bystander; I was rather very much influenced by my previous experience when I drew meanings and made interpretations (Gadamer 1995). After the initial breakdown of the text, a picture emerged of how the thoughts and actions of midwives were heavily dependent on those of superior professionals. This posed a new question: How do midwives and doctors communicate to each other?? A researcher must be open when engaging in dialectic with text; new questions develop as a researcher seeks answers (Ödman 2007). I used the accounts to formulate a basic explanation as to how a midwife (an actor) views her responsibility and participatory role. As I interpreted, I focused on the words used by midwives rather than on their actions per se. Ricoeur (1993) implies that interpretation embraces both understanding and explanation. One explanation may emerge when a researcher becomes aware that the text contains different formulations. Such an explanation is an implied meaning (Selander 2005). Interpretation involves both engagement and aloofness. The hermeneutic principle is important during interpretation; parts of meaning can be understood only in the light of the whole (Ödman 2007). It was only when I looked beyond the current situation, examining how midwives expressed themselves and the care that they gave, that I began to note differences in how they perceived their responsibilities in caring situations and how woman participation varied. I first organized the various formulations into three different groups (categories) in terms of the perception of responsibility in various care situations.

\section{Ethical Considerations}

All midwives in charge of mother-child couples during the study were informed both in writing and verbally of the nature of the study, and that their participation was entirely voluntary. Midwives who formally agreed to participate wrote reflections and gave these to a midwife chosen to collect the information. All midwives were assured that no-one but themselves could access the list of code numbers. In other words, it was impossible to trace the authors of the accounts. The midwives were also assured that the accounts would be carefully stored to prevent their use in other contexts.

The Head of the Clinical Department of the Hospital approved the study; the permit number was 19990104. Formal ethics committee approval is not necessary for 
research involving hospital staff if participants remain anonymous (Codex rules 2011). The hospital adheres to the usual ethical guidelines, and the study adhered to the guidelines governing nursing research in the Nordic countries (NNF 2003).

\section{Findings}

A picture emerged of an organisation within the hospital, a staff hierarchy influenced daily work choices and how midwives cooperated with other staff. This picture, described below, is an input to the results and provides an early understanding of those results. Midwives' responsibilities were then divided into three different categories.

\section{Hierarchy Influenced Relationships with Others}

Midwives often mentioned their relationships with other health-care professionals and then reflected upon how care was designed. To shed light on the environment, and the day-to-day routines of assisting in childbirth and maternity ward care, I wish to offer verbatim quotations that, when combined, create a picture of the absence of the real communication between all involved. However, the very existence of such indirect communication may render it difficult to develop a holistic view of the mother-child relationship. The quotations were chosen to show how midwives allowed themselves to be confined, by other actors, in the context of relationships with mother-child pairs:

Since the child is large, 4485 $\mathrm{g}$, the paediatrician prescribed a blood sugar level check at one hour of age $=1.8$. The child is given formula. The mother is in the recovery room.

The child has not been close to its mother the entire time she has been in the recovery room. No breastfeeding or physical contact with its mother - how does this affect blood sugar level? (ID 65)
The quotation reveals the focus of the paediatrician. The primary interest is the welfare of the child, and s/he prescribes medical measures that will ensure the child's survival. The mother's care of her child is obstructed and breastfeeding is nothing more than a means to feed the child. The use of formula controls child nutrition and is thus perceived as good. A part (the child) is more important than the whole (the mother-child relationship). A mother's participation in the care of her child is not included in the paediatrician's prescription.

The anaesthetist's primary interest is the welfare of the mother, and a mother is held in the recovery room until she is strong enough to move to a ward with fewer monitoring resources. The needs of the child were not taken into consideration when care was organised in this manner:

The child missed out on early contact with its mother due to the mother having been sedated for a c-section. Breastfeeding always gets off to a more difficult start after an emergency c-section, in particular when the mother is sedated.

It would probably be difficult to modify routines to allow the child to be with its mother in the recovery room. (ID 43)

The observation that the child is missing early contact indicates that the midwife thinks that, optimally, mother and baby should be together immediately after labour. However, she has no idea how to address the challenge of modifying the routine. "It would probably be difficult to modify routines". This suggests that the ideas of midwives are not communicated to the medical doctors or taken seriously.

The paediatrician prescribes formula every third hour since the child is too large for date and must constantly be kept under a light source. However, the little girl has sucked well, and it has been 


\begin{abstract}
possible to express colostrum. The child is on the verge of being too large for date, and a blood sugar level of 2.6 is not too low in my opinion. The child might have been able to cope on breast milk combined with weight checks and B-glucose checks. (ID 50)
\end{abstract}

The paediatrician prescribes formula every three hours. The midwife writes "the little girl has sucked well, and it has been possible to express colostrum". Did the paediatrician know these facts? This scenario suggests that the paediatrician did not trust the mother's ability to breastfeed properly. The midwife has a different opinion but chooses not to say anything; the paediatrician has the possibility to decide how to proceed. However, some midwives described how they considered the best way to care for both mother and child and how they acted independently:

The child had breastfed several times.

The child was trembling during rounds. The paediatrician prescribes a blood sugar check; the result is 2.1 and extra formula is prescribed. The mother expresses $12 \mathrm{ml}$ colostrum that I feed by cup. We then continue breastfeeding. (ID 26)

The paediatrician was possibly worried about the baby's trembling noticed during rounds, and therefore prescribed blood glucose testing and formula every three hours. The midwife took responsibility for the situation. Formula was not given and the mother was encouraged to express colostrum. The midwife had faith in the mother's attempt to breastfeed. After colostrum was produced, the mother could start to breastfeed exclusively.

Several midwives also reported that documentation of care was sometimes deficient. It was not always easy to reflect on the care measures that were implemented because the details were sometimes completely missing from patient logs. Only medical data and treatment details were present. The following quotation illustrates this problem:

The first measure was to give formula when blood sugar level was 1.9 at three hours of age.

I have thought about how the child was cared for during the three hours. It was breastfed when it was 20 minutes old, but where was it after that? Did the child become cold? Was it in its own bed or with its mother's? How well was the child dried?

No one checks to see if the mother has colostrum. Couldn't the child have been breastfed again?

Formula was only necessary on one occasion in this case, and I wonder if care routines were optimal.

It is not possible to gauge this based on the journal. (ID 86)

Thus, the midwife's primary responsibility, the care of the mother and child, was not prioritized in journal notes; medical measures took precedence. If knowledge is considered to be an integrated compendium of all prior previous experience and learning, such knowledge allows basic assumptions to be made in terms of what is important. This influences how midwives view and delimit situations of care. Actions are influenced by intentions and values (Alexandersson 1994; Uljens 1989) and develop via a dialectical relationship with the context of our existence. This viewpoint enables a picture to be drawn in which various professionals focus on different parts of the whole (Figure 1). 


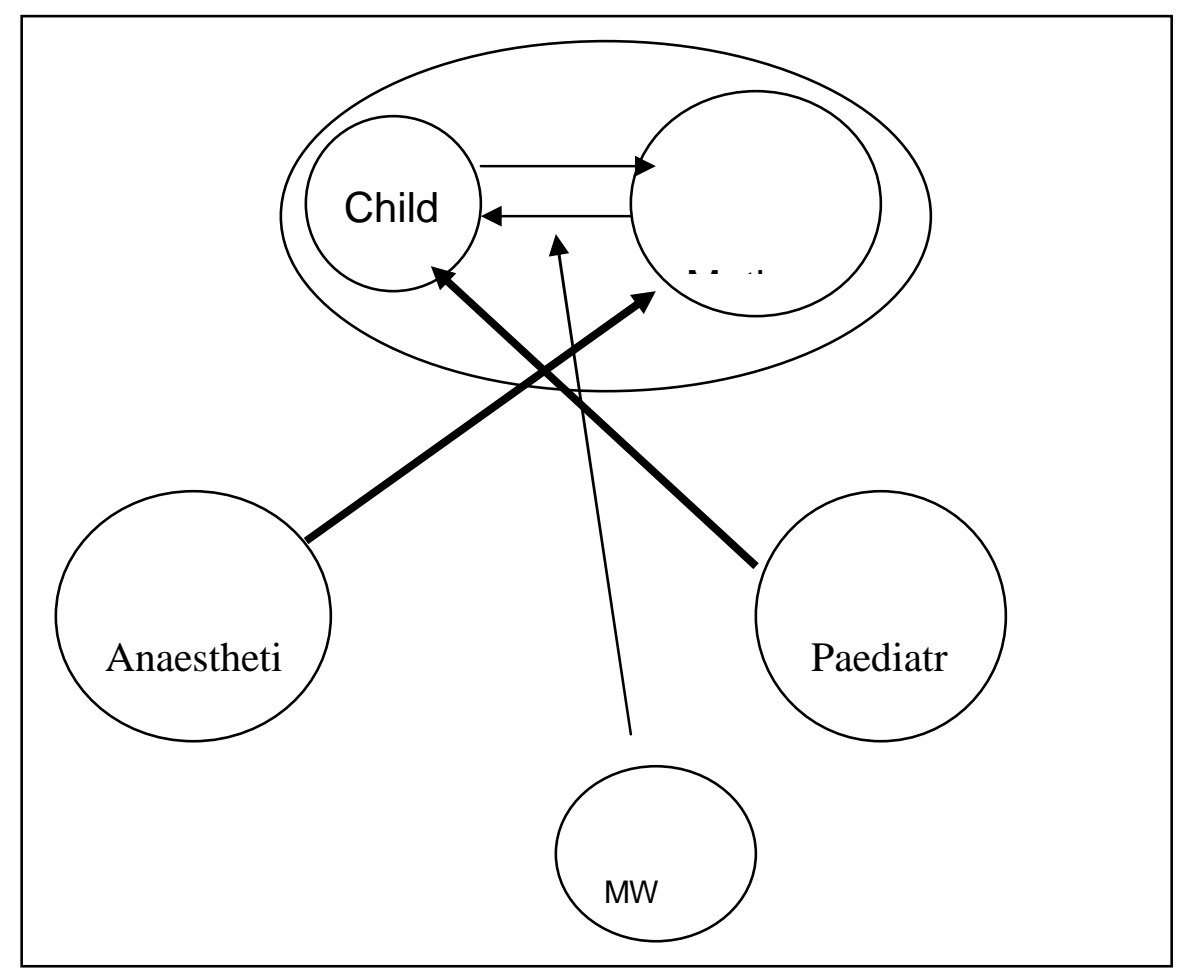

Figure 1: The anaesthetist's primary interest is in the welfare of the mother and the paediatrician's in the welfare of the infant. The midwife is lower in the hierarchy than doctors and learns that her opinions are not as important as those of doctors. The midwife's primary task, to care for both mother and child as a unit, is sometimes problematic.

How Midwives View their Responsibilities in Various Situations

I sought to understand differences in how midwives view their responsibilities in various situations by studying the formulations. As I interpreted, I focused on the words used rather than on the actions per se. Hidden meanings can be revealed when a textual structure is deeply analysed or when a study is made of how words are used (Ricoeur 1993). The results reveal underlying differences in how participation and responsibility were viewed. Three general categories could be discerned: asymmetrical responsibility, symmetrical responsibility, and abdication of responsibility. In the quotes that follow, important words or phrases are in italics.

\section{Asymmetrical Responsibility}

Midwives in this category consider that a midwife is responsible for the correct administration of care. The mother and child must adhere to the prescribed treatment, and resources must be utilised as intended. The trained midwife views herself as the person who knows what is best for the woman; she is more informed than the woman. Thus, this midwife sees herself as being responsible for the mother and child during the time they are in her care. The following quotations are illustrative:

I question if formula was really necessary considering it was possible to breastfeed from the beginning. However the mother was positive to the child receiving extra food. She 
would like to continue giving formula today as well, but $I$ am removing that option so that she will only breastfeed. (ID 99)

When a child is born prematurely and the mother is unable to breastfeed, it is important that the child receive food - in part because the child is premature and in part because the mother has recently been through an operation and needs to relax and not worry about the child. (ID 27)

The midwife of the first quotation is critical to the care being given, and although the mother views formula-feeding positively and would like to continue using formula, the midwife removes "that option." As a midwife, she knows what is best. It is not the mother who chooses the path; rather, the midwife makes that decision. The impression is that the mother does not have a choice even though she is the one who will breastfeed. Independent of the mother's wishes, the midwife decides both how care will be given and what is right and wrong. In the first line she uses the phrase "I question", meaning that she is unsure that the right decision was made before she became involved. The mother, who has been there all along, is not included to participate in decision-making on how to proceed.

In the second quotation, the midwife knows what will relax the mother better than does the mother herself. The midwife believes that if the child is fed, the mother need not worry, and can relax. Both quotations show that midwives make decisions independent of the mothers' input.

Midwives often see themselves as being principally responsible for the infants; this deprives a mother of the ability to make decisions about her child. The midwife believes that she has a greater responsibility than the mother as long as the mother and child are in hospital. The mother's participation in decision-making is secondary:

The mother is unhappy about the_necessity of giving formula by bottle rather than by cup, but I believe this is necessary_due to low sugar values.

We have not had time or been able to express milk from her breasts (the mother has had a headache after the epidural). (ID 42)

Regardless of the action in question, this quotation shows that the mother does not have a great deal to contribute to the care the midwife has time to give, can give, or wants to give. The midwife decides what is and is not necessary.

\section{Symmetrical Responsibility with the Mother}

Midwives in this category consider that they play consultative roles and that they share responsibility with the woman; these midwives sketch a plan of action and reach agreement with the mother. The midwife wants to use her know-how to influence the mother and is happy to share her knowledge through dialogue. Also, the midwife assumes that the woman is interested in controlling her situation, and that each mother is a unique individual with strengths and weaknesses that the midwife should probably understand. Midwife and mother make good logical decisions that both support. The following quotation illustrates this attitude:

This is a secure, lovely mother of 3 who knows a great deal about children and breastfeeding._The little girl became so furious when she was hungry that it was difficult to calm her down so she could breastfeed. Together we agreed that she would begin by expressing a little colostrum with which to calm the little girl. She then breastfed the child, but she [baby] continued to cry. 
We agreed_to give Babysemp temporarily in order to calm the situation down. When she began producing mature milk, the mother started breastfeeding entirely and was able to continue doing so with the right support. (ID 17)

The midwife has a great deal of faith in the mother, whom she sees as secure, lovely, and knowledgeable about children and breastfeeding. The midwife uses words like "together" and "we" and sees her role as a provider of support. The midwife uses the phrase "with the right support", meaning that, with such support, the mother can be competently involved in decision-making. The mother's confidence in her own ability increases if she can trust the midwife for assistance and support.

\section{Tendency to Abdicate Responsibility}

This category contains midwives who think they should follow prescriptions and report deviations to superiors. Such a midwife passes all decision-making to a supervisor and does not personally take a stand or any responsibility for the care administered:

Born in week $42+0,4,530$ $\mathrm{g} / 53 \mathrm{~cm}$.

A C-section was planned for the mother. The child breastfeeds right after the procedure. B-glucose level was 2.7, and formula was prescribed. The child was given $15 \mathrm{ml}$ formula.

Why was the child's Bglucose level checked? Simply because it weighed over 4,500 g?

According to hospital instructions, a baby that is too large for date is subject to be given formula. Must this always be the case, no matter blood sugar level? (ID 51)

The midwife performs tests and follows prescriptions without personally believing that care is optimal; she wonders: "must this always be the case?" The midwife's account can be interpreted as a desire to make individual assessments rather than simply adhering to hospital guidelines. How can the midwife involve the mother in care if that midwife does not personally take part in choosing the care that she administers?

In the same way by which the midwife avoids getting involved in the prescriptions she administers, she also avoids influencing or becoming involved in listening to the mother's views and opinions on the child's care. The following quotation illustrates this:

The child received formula once when the mother asked for it. In reality, breastfeeding is going well. This is the mother's second child, and I believe giving formula is common in her culture. The mother makes her own decisions. (ID 78)

"In reality", the midwife believes that breastfeeding is going well, but refrains from giving her view, or in any other way attempting to influence the mother. Rather, she decides "to believe" that the mother's culture caused her to ask for formula. The mother is able to make decisions on her own without interference from the midwife.

\section{Discussion}

In this study, a picture emerges of an organisation wherein a hierarchy influences the daily work. Such a picture allows the results to be understood. Three general categories of midwives could be identified in terms of the responsibility assumed and the attitude toward woman participation in caring. Midwives are asymmetrically responsible, symmetrically responsible, or abdicate responsibility.

The result indicated an organisation as contained different caregivers focused on parts of the whole rather than on the whole per se. A mother and her newborn were viewed as two separate individuals rather than as an important unit. According to Berg (2005), the result can depend on, 
medical science seeks to discover and avoid risks, while midwives often want to encourage and support normalcy. Collaboration sometimes breaks down as a result of deviation in care/cure perspectives. Competent collaboration further required careful consideration of the impact of professional culture on patient care, finding one's own place within a team and recognizing each other's strength (Suter et.al. 2009). Since values are internalized to the profession, and largely unspoken, they can create important obstacles that may actually be invisible to different team members (Hall 2005). Both asymmetrical responsibility and abdication of responsibility indicate that communication between doctors and midwives, and between midwives and new mothers, is imbalanced. The results are in line with Burns, et al. (2012 and 2013) when they show how midwives often took over infant feeding from the unskilled mother. A genuine dialogue between the midwife and other health care professionals, and between the midwife and the new mother, are necessary to achieve this balance. Instead there are "a prescriptive and authoritative communications styles denied fulfilment of midwife - woman partnerships" (Burns, et .al. 2013 p.71)

A holistic view of a health care organisation focuses on an encounter between two subjects. The patient and the caregiver interact professionally but, at the same time, a relationship develops between two individuals. The need for such an approach is apparent in the results, but it was difficult to make substantial progress in the organisation as it stood. The data are in line with the results obtained when the professional support offered by midwives during labour was examined. It appeared that such support was rather ill-defined in comparison with medical procedures. The principal issue in the hospital was that the quality of professional midwife support was affected by medical ideology (Thorstensson et.al. 2012). A Cartesian medical view of the body may result in midwives' use of language in a way that effectively controls and limits the decision making by the woman, and ensures a superior position in the relationship with the woman (Burns, et .al 2013)

Protecting and promoting breastfeeding requires that the mother and child are viewed as an integrated unit, and the two should be kept together to the maximum extent possible (Svensson et.al 2005). When formula feeding is medically necessary, it is more important than ever that the mother feels part of the decision-making process and important to her child. The Swedish Act on Patient Safety (2010) decrees that planned care should include maternal consultation. This study shows an opposite picture and the result is in line with what Dykes (2005) concluded; the organisational culture in postnatal wards causes midwives to feel unable to establish relationships with mothers. Breastfeeding is based on collaboration between mother and child, and the mother often requires a midwife's support in this process (Karl et.al 2006). A parallel negotiation process is evident in double, first between a mother and her midwife, as well as between the midwife and the doctor. Therefore, good communication between midwives and doctors can be seen as a starting point and a prerequisite for good health.

The decision to ask midwives to write reflections on care was based in part on the importance of being able to ensure anonymity, and in part on my desire to disrupt day-to-day work to the least possible extent. I am a midwife myself, and I know several midwives who recorded reflections; it was thus important that I was unable to associate any account with a specific author. All midwives agreed to share views and opinions, and the 101 accounts cover all children who were receiving formula.

My interpretation of word choice in quickly recorded accounts allowed me, I believe, to discern various conceptions of participation and responsibility. However, this issue should be investigated in more detail, for example via in-depth interviews. The results indicate that midwives do not fall into a unified group in terms of responsibility; different groups undoubtedly exist. 
The data were collected more than 10 years ago, but the questions remain valid today and the results have been presented to both colleagues and a research team. The findings have been recognised as important and are reflected in the care given today. But there is a time lapse since the data were collected, and there is a possibility that different results may be found if the study was conducted now.

\section{Conclusion}

The importance of a good relationship between a new mother and a midwife cannot be overestimated. In the motherinfant context, mothers guide the relationship and respond to signals from their infants. As a mother draws her infant into active interaction, a midwife facilitates the mother's engagement in her own care and that of her newborn. It is therefore necessary to understand that the breastfeeding question poses a challenge that can be met only by true and open minded communication between medical doctors and midwives. Otherwise, it is impossible to keep a holistic view and present a united front to the woman.

\section{References}

1.Alexandersson, M.(1994) Den fenomenografiska forskningsansatsens fokus [Focus of the Phenomenographic Approach]. In Kvalitativ metod och vetenskapsteori [Qualitative Method and Epistemology]. Edited by Starrin B, Svensson P-G. (p:111136). Studentlitteratur, Lund Sweden

2.Berg, M. (2005) A midwifery model of care for childbearing women at high risk: genuine caring in caring for the genuine. Journal of Perinatal Education (14) 9-21.

3.Burns, E., Fenwick, J., Sheehan, A., \& Schmied, V. (2013). Mining for liquid gold: Midwifery language and practices associated with early breastfeeding support. Maternal and Child Nutrition, 9(1), 57-73.

4.Burns, E., Schmied, V., Fenwick, J., \& Sheehan, A. (2012). Liquid gold from the milk bar: Constructions of breastmilk and breastfeeding women in the language and practices of midwives. Social Science and Medicine, 75 (10), 1737-1745.

5.Codex ruels \& quidelines for research (2011)

http://codex.vr.se/en/manniska5.shtml

6.Dykes, F. Moran, V.H. Burt ,S and Edwards, J. (2003) Adolescent mothers and breastfeeding: experiences and support needs--an exploratory study. J Hum Lact. 19(4)391-401

7.Dykes, F.(2005) A critical ethnographic study of encounters between midwives and breast-feeding women in postnatal wards in England. Midwifery 21(3)241-52.

8.Gadamer HG. (1995)Truth and method. The continuum Publishing Company, New York

9.Gill, S. L. (2001) The little things: Perceptions of breastfeeding support. $J$ Obstet Gynecol Neonatal Nurs, 30( 4) 401409

10.Hall, P. (2005). Interprofessional teamwork: Professional cultures as barriers. Journal of Interprofessional Care, 19 (Suppl. 1) 188-196.

11.Karl, D.J. Beal, J.A. O'Hare, C.M. and Rissmiller, P.N. (2006) Reconceptualizing the nurse's role in the newborn period as an 'attacher '. MCN Am J Matern Child Nurs, 31(4) 257-262

12.Klaus, M.H. Kennell, J.H. Klaus, P.H. (1996) Bonding Building the Foundations of Secure Attachment and Independence. Addison-Wesly Publishing Company, Massachusetts USA

13.Ljungberg T.(1995) Vad är Naturligt för Mitt Barn? En Introduktion till hur man som Förälder kan ta hand om sitt Barn på ett mer Naturligt och Biologiskt Ursprungligt Sätt. [What is Natural for My Child? An Introduction to How Parents Can Take Care of Their Children in a More Natural, Biological Way]. Exiris, Nyköping Sweden

14.McInnes, R. J.and Chambers, J, A. (2008) Supporting breastfeeding mothers: 
qualitative synhesis. Journal of Advanced Nursing 62(4)407-427

15.NNF.(2003) Ethical Guidelines for Nursing Research in The Nordic Countries. Nordic Nursing Federation, Oslo

16. Ricoeur, P. (1993) Från text till handling: en antologi om hermeneutik. [From text to action]: [An anthology on hermeneutics] (M. Fatton, B. Kristensson Uggla, P. Kemp, Trans.). Brutus Östlings Bokförlag, Symposion AB, Stockholm/Stehag Sweden

17.Schmied, V., Beake, S., Sheehan, A., McCourt, C., \& Dykes, F. (2011). Women's perceptions and experiences of breastfeeding support: A metasynthesis. Birth, vol 38, no. 1, pp 49-60.

18.Selander, S. (2005) Didaktisk hermeneutik och samhällsvetenskapernas interpretatoriska karaktär [Didactic hermeneutics and of the social sciences interpretive nature ]. In: Text \& Existens: Hermeneutik möter samhällsvetenskap [Text \& Existence: Hermeneutics meets social science] Edith by S. Selander \& P-J.Ödman. (p:43-79) Daidalos, Göteborg Sweden

19.SFS 2010:659. Patientsäkerhetslagen. [patient safty act] http://www.riksdagen.se/sv/DokumentLag ar/Lagar/Svenskforfattningssamling/Patien tsakerhetslag-2010659_sfs-2010659/?bet=2010:659

20.Simkin, P. (1996) The experience of maternity in a woman's life. J Obstet Gynecol Neonatal Nurs, 25(3) 247-252

21.Stern, D. N. Bruschweiler-Stern, N. and Freeland, A.(1999) En mor blir till : Hur moderskap förändrar dig för all framtid. [The birth of a mother]. Natur och kultur, Stockholm Sweden

22.Suter, E. Arndt, J. Arthur, N. Parboosingh, J. Taylor, E. and Deutschlander, S. (2009)Role understanding and effective communication as core competencies for collaborative practice Journal of Interprofessional Care 23(1) 41-51
23.Svensson, K, Matthiesen, A.S. and Widström, A-M. (2005) Night Rooming-in Who Decides? An Example of Staff Influence on Mother's Attitude. Birth (32) 99-106

24.The National Board of Health and Welfare.(2012) Samverka med patienten [Cooperation with the patient] http://www.socialstyrelsen.se/patientsaker het/forebygga/samverkamedpatienten

25.Thorstensson, S. Ekstrom, A. Lundgren, I. and Hertfelt Whan, E.(2012) Exploring Professional Support Offered by Midwives during Labour: An Observation and Interview Study. Nursing Research and Practice doi:10.1155/2012/648405

26. Uljens, M.(1989) Fenomenografi forskning om uppfattningar [Phenomenografic - research on perceptions] Studentlitteratur, Lund, Sweden

27.Zwedberg, S. Wickman, M. Negussie, B.(2003) How children were brought up in maternity hospitals in Stockholm: A study in the spring 1999 [Swedish].Vard I Norden [Nursing Science and Research in the Nordic Countries] 23(3)21-26.

28.Zwedberg, S. (2010) I wanted to breastfeed! A Hermeneutical Study of Mothers with Breastfeeding Problems; Their Experinces, Coping strategies, and Consultative Meetings with Midwives. Doctoral thesis nr 165, The Institute of Education, Stocholm University Sweden

29.Zwedberg, S. and Naeslund, L.(2011) Different attitudes during breastfeeding consultations when infant formula was given: a phenomenographic approach. International Breastfeeding Journal (6):1

30.Ödman, P-J. (2007)Tolkning, förståelse, vetande: hermeneutik $i$ teori och praktik [Interpretation, understanding, knowledge: hermeneutics in theory and practice]. Norstedts akademiska förlag, Stockholm Sweden 